IZA DP No. 9695

The Effect of Degree Attainment on Arrests:

Evidence from a Randomized Social Experiment

Vikesh Amin

Carlos A. Flores

Alfonso Flores-Lagunes

Daniel J. Parisian

January 2016 


\title{
The Effect of Degree Attainment on Arrests: Evidence from a Randomized Social Experiment
}

\author{
Vikesh Amin \\ Central Michigan University
}

Carlos A. Flores

California Polytechnic State University

Alfonso Flores-Lagunes

Syracuse University and IZA

\author{
Daniel J. Parisian
}

Mississippi State University

Discussion Paper No. 9695
January 2016

IZA

P.O. Box 7240

53072 Bonn

Germany

Phone: +49-228-3894-0

Fax: +49-228-3894-180

E-mail: iza@iza.org

Any opinions expressed here are those of the author(s) and not those of IZA. Research published in this series may include views on policy, but the institute itself takes no institutional policy positions. The IZA research network is committed to the IZA Guiding Principles of Research Integrity.

The Institute for the Study of Labor (IZA) in Bonn is a local and virtual international research center and a place of communication between science, politics and business. IZA is an independent nonprofit organization supported by Deutsche Post Foundation. The center is associated with the University of Bonn and offers a stimulating research environment through its international network, workshops and conferences, data service, project support, research visits and doctoral program. IZA engages in (i) original and internationally competitive research in all fields of labor economics, (ii) development of policy concepts, and (iii) dissemination of research results and concepts to the interested public.

IZA Discussion Papers often represent preliminary work and are circulated to encourage discussion. Citation of such a paper should account for its provisional character. A revised version may be available directly from the author. 


\title{
ABSTRACT \\ The Effect of Degree Attainment on Arrests: Evidence from a Randomized Social Experiment ${ }^{*}$
}

\begin{abstract}
We examine the effect of educational attainment on criminal behavior using random assignment into Job Corps (JC) - the United States' largest education and vocational training program for disadvantaged youth - as a source of exogenous variability in educational attainment. We allow such random assignment to violate the exclusion restriction when used as an instrument by employing nonparametric bounds. The attainment of a degree is estimated to reduce arrest rates by at most 11.8 percentage points (about $32.6 \%$ ). We also find suggestive evidence that the effects may be larger for males relative to females, and larger for black males relative to white males. Remarkably, our 95 percent confidence intervals on the causal effect of education on arrests are very similar to the corresponding confidence intervals on the same effect from studies exploiting changes in compulsory schooling laws as an instrumental variable in the estimation of the effect of education on arrest rates (e.g., Lochner and Moretti, 2004).
\end{abstract}

JEL Classification: $\quad$ 12, K42

Keywords: degree attainment, arrests, crime, social experiments

Corresponding author:

Alfonso Flores-Lagunes

Department of Economics and Center for Policy Research

Syracuse University

426 Eggers Hall

Syracuse, NY 13244-1020

USA

E-mail: afloresl@maxwell.syr.edu

\footnotetext{
* We benefited from comments by the following conference discussants: Robynn Cox at the "Hispanic Economic Issues" conference organized by the American Society of Hispanic Economists and the Atlanta Fed, Pia Orrenious at the 2014 Southern Economics Association meetings, Jose Manuel Fernandez at the 2015 ASSA meetings, and Jorgen Hansen at the 2015 Western Economics Association International Conference. We have also benefited from comments by participants at the 2015 NY Camp Econometrics, the Conference in honor of Ron Oaxaca organized by the University of Arizona, the Workshop on Social and Labour Market Policy Evaluation with Administrative Data organized by the Luxembourg Institute of Socio-Economic Research (LISER), and the Center for Policy Research (CPR) at Syracuse University.
} 


\section{Introduction}

Crime is an important public policy issue in the U.S. Despite falling crime rates since the 1980s, the U.S. incarceration rate is still more than 6 times that of the typical OECD nation (Kearney et al., 2014). Crime has significant negative effects on the mental wellbeing of both victims and nonvictims. Juvenile incarceration can also have lasting impacts on a young person's future (Aizer and Doyle, 2015). Moreover, youth from low-income families engage in riskier criminal behavior relative to higher-income counterparts (Kearney et al., 2014). Spending on police and law enforcement is the traditional policy mechanism to reduce crime. Policies to promote education attainment could present an alternative (e.g., Lochner, 2011).

Recent studies using variation in education arising from changes in compulsory schooling laws (CSLs) find that there are relatively large crime reducing effects of education. In their seminal paper, Lochner and Moretti (2004; hereafter LM) find that a one year increase in average education in the U.S. reduces state level arrest rates by 15\%. Anderson (2014) estimates the reduced form effect of CSLs on crime in the U.S. He finds that exposure to a minimum dropout age of 18 reduces arrest rates of 16-18 year old males by $17 \%$. An extra year of education reduces the conviction rate of men by $6.7 \%$ in Sweden (Hjalmarrson, Holmlund and Lindquist, 2015) and 21\% in the UK (Machin, Marie, and Vujić, 2011). Both Hjalmarrson Holmlund, and Lindquist (2015) and Machin Marie, and Vujić (2011) also find no evidence of a causal effect of education on convictions for women. Stephens and Yang (2014) is the only study that we are aware of that does not find a causal effect of education on the probability of being incarcerated in the U.S. ${ }^{1}$

We contribute to the evidence on the effect of education on crime by estimating the effect of obtaining a high school, General Educational Development (GED), or vocational degree on arrests using an alternative source of exogenous variation in education under relatively weak assumptions. Specifically, we exploit exogenous variation from a randomly assigned U.S. training program for disadvantaged youth (Job Corps or JC) that generated significant variation in educational attainment. This population of eligible applicants to the training program (aged 16 to 24) is of policy interest since its educational attainment is low and is at a high risk of committing crimes.

Importantly, our work complements the literature using CSLs in several ways. First, that literature usually focuses on teenagers, who are likely to be affected by CSLs, while the intervention

${ }^{1}$ In their table 2, column 2, Stephens and Yang (2014) use similar census data, method, and specification to LM (2004). The different results seem to be due to Stephens and Yang (2004) employing a more refined measure of CSLs that accounts for the timing of school requirement changes. 
we consider affected the educational attainment of 16 to 24 year olds. Second, we consider other types of education besides high school, such as GED and vocational degrees, which in some cases may be better suited for disadvantaged youths. Third, since CSLs are not randomly assigned, a potential threat to using them as a source of exogenous variation is that they could be endogenous. Indeed, some researchers have cast doubt on their exogeneity (e.g., Lang and Kropp, 1986; Stephens and Yang, 2014). Instead, we exploit exogenous variation coming from a randomized experiment. Fourth, in contrast to studies using CSLs as instruments-which require that all of the effect of CSLs on crime outcomes is only due to an increase in education - we let our instrument (random assignment to JC) violate the exclusion restriction by allowing it to have a direct effect on arrests; that is, we let assignment to JC affect arrests through channels other than education. We replace the exclusion restriction assumption with weak monotonicity assumptions on average potential outcomes. ${ }^{2}$ Finally, the instrument we consider has a large effect on the education attainment of the individuals in our sample (about an 80\% effect). In contrast, CSLs typically have modest effects on educational attainment (e.g., in LM (2004) the effect of CSLs on the probability of completing high school was $3 \%$ to $5 \%$ ). In exchange for those potential benefits, we forgo point identification and instead use nonparametric bounds to estimate, under relatively weak assumptions, a range of values where the true causal effect of education on arrests lies.

Remarkably, in spite of using a different source of exogenous variability, methodology, and sample, our 95 percent confidence interval on the causal effect of education on arrests is very similar to the corresponding confidence interval on the same effect from studies exploiting changes in CSLs as an instrumental variable in the estimation of the effect of education on arrest rates. We interpret this finding as providing more confidence that both approaches may indeed be pointing to plausible values where the true effect of education on arrests lies. ${ }^{3}$

A final contribution of the present work is to provide separate analyses of the relationship between education and arrests for different demographic groups by gender and race/ethnicity, and for different types of degrees attained. This is important since few studies report effects for different demographic groups (especially by race/ethnicity), while the lifetime likelihood of imprisonment

\footnotetext{
${ }^{2}$ We do not take a stand as to whether CSLs are exogenous and satisfy the exclusion restriction assumption when used as instruments in this context. Indeed, as noted before, our purpose is to provide complementing evidence by focusing on a different source of exogenous variability in education and employing a different methodology.

${ }^{3}$ Consistency of results across studies employing different sources of variation, populations, and methods is a critical and commonly-used criteria for evaluating causality in fields like epidemiology, as it increases the confidence that a causal relation has indeed been found (see, e.g., Stein and Kline, 1983).
} 
varies widely over these groups. For instance, as of 2009, the lifetime likelihood of imprisonment was 5.9, 32, and 17 percent for white, black, and Hispanic males, respectively (Cox, 2010). Even fewer studies report crime-reducing effects of different education types, while there is evidence of differential financial effects between high school and GED degrees (Heckman and LaFontaine, 2006, 2010).

\section{Job Corps and the National Job Corps Study Data}

\section{$2.1 \quad$ Job Corps}

We analyze the effect of earning a degree on the probability of being arrested employing data from the National Job Corps Study (NJCS). Job Corps is a comprehensive education and vocational training program that provides free services to economically disadvantaged youths (aged 16-24) in the U.S. Its goals are to educate, train, and prepare adolescents and young adults for employment in purposeful careers, allowing them to live independently. To achieve its goals, JC provides academic and vocational training leading to the attainment of degrees (high school or GED) or certificates in a myriad of trades. In addition, JC offers other services such as residential accommodation, social skills training, counseling, health services, and job placement. These services are delivered nationwide through 125 centers located across the U.S. and Puerto Rico that service roughly 60,000 new applicants each year.

Admittance into JC requires that applicants meet a set of criteria regardless of their location. The applicants must: (1) be a legal U.S. resident; (2) be between the ages of 16 to 24; (3) have registered with the Selective Service System if a male over the age of 18; (4) have parental consent if under the age of $18 ;(5)$ be economically disadvantaged; ${ }^{4}$ (6) live in an environment that limits the number of opportunities to participate in other programs; (7) need additional education, training, or job skills; (8) be free of serious behavioral issues; ${ }^{5}$ (9) have a clean bill of health; (10) have found sufficient child care arrangements while actively participating in the program; and (11) posses the capability and aspirations to benefit from JC. The certification of these JC requirements is conducted by program-affiliated outreach and admissions offices. The characteristics of the population of JC applicants largely overlap with those of the relevant population in what pertains

\footnotetext{
${ }^{4}$ Being economically disadvantaged, as defined by JC, means that the applicant's family receives public assistance (e.g., welfare or food stamps) and/or has an income that falls well below the poverty line.

${ }^{5}$ Behavioral issues is somewhat broadly defined. This allows individuals who have been previously arrested to still be eligible for JC participation (Schochet et al., 2003).
} 
to societal crime concerns (Kearney et al., 2014), and it is likely similar to the population that is affected by the CSLs (i.e., youth at risk of dropping out who would remain in school only due to the CSL).

Once enrolled, participants are given the opportunity to participate in a plethora of courses and services. Although the offerings may vary slightly from center to center, the aim of the program remains constant: provide a comprehensive education or vocational training experience to young, disadvantaged individuals. The educational curriculum provides classes in academic and vocational skills training environments (most JC participants enroll in both), which lead to the attainment of degrees or certificates - our treatment of interest. The academic track emphasizes the traditional skill sets learned in a high school setting (reading, writing, and math skills), with an end goal of a high school or GED degree. There is an explicit steering towards GED over high school degrees within JC (Schochet et al., 2001). Vocational training programs vary by center in an attempt to better prepare JC graduates for jobs in their local area. The vocational training programs typically cover the areas of business and clerical, health, culinary arts and hospitality, and building and construction (e.g., carpentry, electrical, plumbing, HVAC). JC centers adhere to an openexit educational philosophy that allows instruction to be individualized and self-paced; however, students can only be enrolled for an absolute maximum of 24 months. The average program duration for participants in JC is eight months (Schochet et al., 2001).

In addition to its educational offerings, JC provides numerous services to its students while enrolled in, as well as after completing the program. The highlight of the JC program is its residential nature, with most $\mathrm{JC}$ participants residing at the $\mathrm{JC}$ center they attend (only about $12 \%$ of participants are non-residential). This feature is important in our context because it implies that the scope of opportunities to engage in crime for JC participants is small given the adult supervision available within JC center residences. Indeed, JC participants likely experience arrest reductions through an incapacitation effect during their enrollment in the program. Additionally, JC provides participants with health and supportive services, the latter of which includes a stipend for the time enrolled in the program, counseling, and social skills training. When a student is preparing to exit the program and seek employment, JC placement agencies assist participants in all aspects of the job search process. Given the availability of these non-educational services to JC participants, it is important that we allow our instrument (random assignment into JC) to have an effect on arrests independently from degree attainment. 


\subsection{The National Job Corps Study}

The National Job Corps Study (NJCS) was a randomized social experiment that began in 1993 with funding from the U.S. Department of Labor. Conducted by Mathematica Policy Research, Inc. (MPR), its task was to examine the effectiveness of JC over a wide range of categories, including program experiences and enrollment, the education and vocational training programs, labor market outcomes (e.g., earnings and employment), crime, and drug and alcohol use. The NJCS was conducted on all existing centers in the 48 contiguous states and the District of Columbia, virtually making it nationally representative. Intake into JC (and the NCJS) ran from November 1994 to February 1996. During this period, outreach and admissions counselors sent MPR lists containing the pre-screened, eligible pool of applicants $(80,833)$ to be randomly assigned to either a control group $(5,977)$, a treatment group $(9,409)$, or a non-research group (Schochet et al., 2001). The control group was barred from enrolling in JC for three consecutive years, although these individuals were allowed to enroll in other educational and training programs. ${ }^{6}$ The treatment group members, upon notification about which center they were assigned to, were eligible to immediately enroll in JC, and most participants did so within the first month. Following random assignment and a baseline interview, the NJCS sample had follow-up interviews at 12-, 30-, and 48-months after random assignment. ${ }^{7}$

The random assignment in the NJCS was subject to noncompliance. Among eligible applicants that were allowed to enroll in JC (the treatment group), about 27 percent did not enroll in JC. Non-compliance was less of an issue for the control group, as only $1.4 \%$ of these individuals were able to enroll in JC before their three-year embargo ended. For this reason, the NJCS (e.g., Schochet et al., 2001) gave emphasis to estimation of intention-to-treat effects, which estimate the effects of random assignment and can be interpreted as the effects of the availability of the JC program. The NJCS also reported effects "per participant" estimated using random assignment as an instrumental variable for actual enrollment in JC. Importantly, this noncompliance has only a minor interpretation consequence for our estimates (see footnote 12 in the next section).

\footnotetext{
${ }^{6}$ Indeed, $72 \%$ of the control group individuals enrolled in educational and training programs and $27 \%$ earned degrees during the time covered by the NJCS.

${ }^{7}$ The baseline interview was conducted after random assignment, resulting in a response rate of 95 percent. Response rates for the 12-, 30-, and 48-month follow-up interviews remained high at 90, 79, and 80 percent, respectively (Schochet et al., 2001). Throughout the analysis below, we utilize NJCS-supplied probability weights to account for interview non-response items and the different sampling into control and treatment groups for some individuals. The construction of these sample weights is described in Schochet (2001).
} 
Using differences-in-means estimates of the intention-to-treat parameter, Schochet et al. (2001) finds significant negative effects of random assignment to JC on the incidence of arrests. Specifically, the NJCS reports the reduction in arrests to be 3.7 percentage points over the entire follow-up period (a reduction of $11.35 \%$ relative to the control mean), the result of $32.6 \%$ of the control group members reporting arrests compared to $28.8 \%$ of the treatment group members. The largest reduction in arrest rates is observed over the first year after randomization with arrests being reduced by $30 \%$, then decreasing to around $10 \%$ over each of the next 3 years, which they attribute to the incapacitation effect of JC. The estimated effect per participant on arrests is a statistically significant -5.2 percentage points (a reduction of $15.8 \%$ relative to the control mean). The NJCS also estimated the effects of JC on arrests for some subgroups. Based on per-participant estimates, Schochet et al. (2008) report reductions in the arrest rates for whites, blacks, and Hispanics, although the effect is only statistically significant for whites and blacks at 5.9 and 5.4 percentage points, respectively. With regards to gender, both male and females are estimated to experience reductions in their arrest rates (6.8 and 2.2 percentage points; $15.6 \%$ and $13.3 \%$, respectively), with only the reduction for males being statistically significant.

Another relevant component of the NJCS for the present work relates to the findings of the impact of random assignment on the educational and vocational achievements of the sample. While nearly $80 \%$ of those applying to JC lacked a high school diploma or GED certificate, $47 \%$ of treatment group individuals that fall into this category earned one of the aforementioned credentials by the study's end, compared to $27 \%$ of the control group. Schochet et al. (2001) document that treatment group members receive, on average, 1,581 hours of educational instruction and training over the study period, compared to only 853 hours for the control group members (recall that the control group members were prevented from enrolling in JC, but they were not barred from entering other programs). Overall, 5.3 (7.5), 42 (27), and 38 (15) percent of the treatment (control) group members receive a high school diploma, GED, or vocational degree, respectively. Given the extensive gains in education and training - and particularly degree attainment - that treatment group members receive, random assignment to JC represents a strong potential instrument for degree attainment.

\subsection{Data and Descriptive Statistics}

Our sample comes from the public-use NJCS data set, and is thus representative of the population of eligible applicants to JC in 1994-1996 in the contiguous U.S. It consists of 7,953 youth (3,161 
assigned to the control group and 4,792 to the treatment group), of which 4,724 are male, 3,229 female, 3,979 black, 2,036 white, and 1,404 Hispanic. This sample is smaller than the originally randomized sample of 15,386 individuals in the NJCS. It has been documented (e.g., Schochet et al., 2001; Schochet et al., 2008) that non-response in the different survey follow-ups in the NJCS results in about 26 percent attrition. However, our use of NJCS-supplied probability weights ameliorate this attrition since they account for interview non-response items (Schochet, 2001). Specifically, in our sample, we lose 4,385 observations due to survey non-response and due to missing key baseline characteristics, and 314 observations due to missing values in individuals' arrest history. Additionally, we drop 2,734 individuals who already had a degree at the time of the baseline interview, so that individuals in the sample start off without degrees. Given that degree attainment at baseline is a pre-treatment characteristic, the observations dropped are balanced between treatment and control groups. Overall, the sample we use is similar in size to other analyses using NJCS data, such as Lee (2009), Flores and Flores-Lagunes (2013), Blanco et al. (2013), Eren and Ozbeklik (2014), and Bampasidou et al. (2014).

Before presenting summary statistics of our sample, recall that we will employ the indicator for random assignment to JC (treatment group) in the NJCS as an instrumental variable. Our treatment variable of interest is an indicator for degree attainment (whether or not it was earned in JC) between random assignment and the 8 subsequent quarters. Our outcome variable is an indicator for having been arrested between quarters 1 and 16 after randomization (the latter is the last quarter of the follow-up period in the NJCS). ${ }^{8}$ Given the 4-year window in which the individuals are followed, it is important to carefully construct the treatment and outcome variables. For this reason, for each individual in the sample, we "start the clock" to measure these variables at the week in which randomization took place, counting either 8 or 16 quarters after this week, for degree attainment or incidence of arrests, respectively. Regarding the outcome, note that its measurement overlaps in timing with the measurement of degree attainment. We do this to capture both the incapacitation and opportunity cost effects of education (for many individuals the first eight quarters would represent incapacitation effects), and because it has been documented (e.g., Schochet et al., 2001) that the effects of the program on arrests are considerably higher during the first year. Nevertheless, a potential concern is that of "reverse causality" - that being arrested could affect whether an individual attains a degree. In Section 4 we also undertake an analysis in

\footnotetext{
${ }^{8}$ The arrest indicator is constructed from self-reports. There is evidence that the NJCS data on arrests appears to be consistent with official crime records (Needels and Burghardt, 2000).
} 
which arrest outcomes are considered after the timing allowed for degree attainment (i.e., quarters 9 through 16), which yields largely similar results.

Table 1: Summary Statistics of Selected Variables for Full Sample and by Gender

\begin{tabular}{|c|c|c|c|c|}
\hline Variable & Full & Males & Females & $\begin{array}{c}\text { Difference } \\
\text { Males - Females }\end{array}$ \\
\hline \multicolumn{5}{|l|}{ Selected demographic variables at baseline } \\
\hline \multirow[t]{2}{*}{ Female } & 0.420 & - & - & - \\
\hline & $(0.006)$ & - & - & - \\
\hline \multirow[t]{2}{*}{ Age } & 17.702 & 17.663 & 17.757 & $-0.094^{* *}$ \\
\hline & $(0.019)$ & $(0.025)$ & $(0.031)$ & $(0.040)$ \\
\hline \multirow[t]{2}{*}{ White } & 0.261 & 0.297 & 0.211 & $0.086^{* * *}$ \\
\hline & $(0.005)$ & $(0.007)$ & $(0.007)$ & $(0.010)$ \\
\hline \multirow[t]{2}{*}{ Black } & 0.496 & 0.469 & 0.534 & $-0.065^{* * *}$ \\
\hline & $(0.006)$ & $(0.012)$ & $(0.006)$ & $(0.013)$ \\
\hline \multirow[t]{2}{*}{ Hispanic } & 0.174 & 0.165 & 0.185 & $-0.020^{* *}$ \\
\hline & $(0.004)$ & $(0.005)$ & $(0.007)$ & $(0.009)$ \\
\hline \multirow[t]{2}{*}{ Married } & 0.033 & 0.020 & 0.050 & $-0.030 * * *$ \\
\hline & $(0.002)$ & $(0.002)$ & $(0.004)$ & $(0.004)$ \\
\hline \multirow[t]{2}{*}{ Has child/children } & 0.163 & 0.086 & 0.268 & $-0.182^{* * *}$ \\
\hline & $(0.004)$ & $(0.004)$ & $(0.008)$ & $(0.009)$ \\
\hline \multicolumn{5}{|l|}{ Selected education and crime variables } \\
\hline \multirow[t]{2}{*}{ Highest grade completed at baseline } & 9.623 & 9.588 & 9.672 & $-0.084^{* * *}$ \\
\hline & $(0.015)$ & $(0.019)$ & $(0.024)$ & $(0.030)$ \\
\hline \multirow[t]{2}{*}{ Degree attained by quarter 8} & 0.286 & 0.271 & 0.308 & $-0.038 * * *$ \\
\hline & $(0.005)$ & $(0.006)$ & $(0.008)$ & $(0.010)$ \\
\hline \multirow[t]{2}{*}{ Ever been arrested by baseline } & 0.275 & 0.338 & 0.188 & $0.149^{* * *}$ \\
\hline & $(0.005)$ & $(0.007)$ & $(0.007)$ & $(0.010)$ \\
\hline \multirow[t]{2}{*}{ Arrested between baseline and quarter 16} & 0.331 & 0.443 & 0.175 & $0.268^{* * *}$ \\
\hline & $(0.005)$ & $(0.007)$ & $(0.007)$ & $(0.010)$ \\
\hline \multicolumn{5}{|l|}{ Selected labor market variables at baseline } \\
\hline \multirow[t]{2}{*}{ Employed } & 0.617 & 0.638 & 0.589 & $0.048^{* * *}$ \\
\hline & $(0.005)$ & $(0.007)$ & $(0.009)$ & $(0.011)$ \\
\hline \multirow[t]{2}{*}{ Weekly earnings } & 117.30 & 130.86 & 98.57 & $32.29 * * *$ \\
\hline & $(1.43)$ & $(1.98)$ & $(1.99)$ & $(2.80)$ \\
\hline Observations & 7,953 & 4,724 & 3,229 & \\
\hline
\end{tabular}

Table 1 presents the average of selected characteristics at baseline for the full sample, males and females, as well as the difference between the average characteristics for the two genders. The selected characteristics at baseline include demographics, education and crime related variables, and employment and earnings information. The first column (for the full sample) shows that the average JC applicant who did not have a degree at baseline is a black male who is about 17.7 years old, not married, and has no children. With regards to education, the average applicant has completed a little more than 9.6 years of schooling, and $29 \%$ of applicants earn at least one degree within 8 quarters from randomization. Furthermore, about $61.7 \%$ of applicants are employed at 
baseline and earn around $\$ 117$ per week; while $27.5 \%$ have an arrest history at baseline and $33 \%$ will be arrested within 16 quarters after randomization. There are stark differences between males and females, as can be seen in the last column of Table 1. Males are significantly more likely to be white, younger, not married and without children, have lower academic achievements, and be involved in criminal activity (both at baseline and by quarter 16) than their female counterparts. With regards to labor market outcomes, the average male JC applicant has higher weekly earnings at baseline and is more likely to be employed.

Table 2: Summary Statistics of Selected Variables for Males, by Race/Ethnicity

\begin{tabular}{|c|c|c|c|c|c|c|}
\hline \multirow[b]{2}{*}{ Variable } & \multirow[b]{2}{*}{ Black } & \multirow[b]{2}{*}{ White } & \multirow[b]{2}{*}{ Hispanic } & \multicolumn{3}{|c|}{ Sample Differences } \\
\hline & & & & Bl. - Wh. & Bl. - Hisp. & Hisp. - Wh. \\
\hline \multicolumn{7}{|l|}{ Selected demographic variables at baseline } \\
\hline Age & $\begin{array}{l}17.599 \\
(0.036)\end{array}$ & $\begin{array}{l}17.627 \\
(0.044)\end{array}$ & $\begin{array}{l}17.759 \\
(0.064)\end{array}$ & $\begin{array}{l}-0.028 \\
(0.057)\end{array}$ & $\begin{array}{c}-0.160^{* *} \\
(0.073)\end{array}$ & $\begin{array}{c}0.132 \\
(0.078)\end{array}$ \\
\hline Married & $\begin{array}{c}0.010 \\
(0.002)\end{array}$ & $\begin{array}{c}0.021 \\
(0.004)\end{array}$ & $\begin{array}{c}0.041 \\
(0.007)\end{array}$ & $\begin{array}{c}-0.011^{* *} \\
(0.004)\end{array}$ & $\begin{array}{c}-0.030^{* * *} \\
(0.007)\end{array}$ & $\begin{array}{c}0.020^{* *} \\
(0.008)\end{array}$ \\
\hline Has child/children & $\begin{array}{c}0.098 \\
(0.006)\end{array}$ & $\begin{array}{c}0.052 \\
(0.006)\end{array}$ & $\begin{array}{c}0.120 \\
(0.012)\end{array}$ & $\begin{array}{c}0.047^{* * * *} \\
(0.009)\end{array}$ & $\begin{array}{c}-0.021 \\
(0.013)\end{array}$ & $\begin{array}{c}0.068^{* * *} \\
(0.013)\end{array}$ \\
\hline \multicolumn{7}{|l|}{ Selected education and crime variables } \\
\hline Highest grade completed at baseline & $\begin{array}{c}9.623 \\
(0.026)\end{array}$ & $\begin{array}{c}9.591 \\
(0.034)\end{array}$ & $\begin{array}{c}9.516 \\
(0.047)\end{array}$ & $\begin{array}{c}0.032 \\
(0.043)\end{array}$ & $\begin{array}{c}0.106^{* *} \\
(0.054)\end{array}$ & $\begin{array}{l}-0.075 \\
(0.058)\end{array}$ \\
\hline Degree attained by quarter 8 & $\begin{array}{c}0.244 \\
(0.009)\end{array}$ & $\begin{array}{c}0.317 \\
(0.012)\end{array}$ & $\begin{array}{c}0.261 \\
(0.016)\end{array}$ & $\begin{array}{c}-0.073^{* * *} \\
(0.015)\end{array}$ & $\begin{array}{l}-0.016 \\
(0.018)\end{array}$ & $\begin{array}{c}-0.057^{* * *} \\
(0.020)\end{array}$ \\
\hline Ever been arrested by baseline & $\begin{array}{c}0.318 \\
(0.010)\end{array}$ & $\begin{array}{c}0.374 \\
(0.013)\end{array}$ & $\begin{array}{c}0.329 \\
(0.017)\end{array}$ & $\begin{array}{c}-0.055^{* * *} \\
(0.016)\end{array}$ & $\begin{array}{c}-0.011 \\
(0.019)\end{array}$ & $\begin{array}{c}-0.045^{* * *} \\
(0.021)\end{array}$ \\
\hline Arrested between baseline and quarter 16 & $\begin{array}{c}0.467 \\
(0.011)\end{array}$ & $\begin{array}{c}0.439 \\
(0.013)\end{array}$ & $\begin{array}{c}0.397 \\
(0.017)\end{array}$ & $\begin{array}{c}0.027 \\
(0.017)\end{array}$ & $\begin{array}{c}0.070 * * * \\
(0.020)\end{array}$ & $\begin{array}{l}-0.043 \\
(0.022)\end{array}$ \\
\hline \multicolumn{7}{|l|}{ Selected labor market variables at baseline } \\
\hline Employed & $\begin{array}{c}0.574 \\
(0.010)\end{array}$ & $\begin{array}{c}0.731 \\
(0.012)\end{array}$ & $\begin{array}{c}0.656 \\
(0.017)\end{array}$ & $\begin{array}{c}-0.158^{* * *} \\
(0.016)\end{array}$ & $\begin{array}{c}-0.083^{* * *} \\
(0.020)\end{array}$ & $\begin{array}{c}-0.075^{* * *} \\
(0.021)\end{array}$ \\
\hline Weekly earnings & $\begin{array}{c}107.33 \\
(2.55)\end{array}$ & $\begin{array}{l}164.71 \\
(4.00)\end{array}$ & $\begin{array}{c}133.27 \\
(4.79)\end{array}$ & $\begin{array}{c}-57.38^{* * *} \\
(4.75)\end{array}$ & $\begin{array}{c}-25.94^{* * *} \\
(5.43)\end{array}$ & $\begin{array}{c}-31.44^{* * *} \\
(6.24)\end{array}$ \\
\hline Observations & 2,223 & 1,394 & 783 & & & \\
\hline
\end{tabular}

Note: Standard errors in parentheses.

** and *** indicate significance at the 95 and 99 percent confidence levels, respectively.

Due to the lower incidence of arrests and smaller sample for females relative to males, our analysis with regards to race/ethnicity focuses on males. Table 2 shows the average of selected characteristics for black, Hispanic, and white males, as well as the differences between each of the subgroups. White applicants are more likely to earn a degree within two years of randomization, ever been arrested by baseline, and be employed and have higher weekly earnings at baseline, while they are less likely to have had children by the baseline interview. Additionally, white males are more (less) likely to be married than their black (Hispanic) counterparts, while blacks are more 
likely to be younger than Hispanic applicants. Compared to black males, Hispanic males are more likely to be employed and married at baseline, and also earn almost $\$ 26$ a week more on average. Although black males have completed higher grades than Hispanics at the baseline interview, they are more likely to be arrested between baseline and quarter 16 after randomization.

Table 3 presents summary statistics of selected variables for each of the samples by degree attainment status by quarter 8 . For the full sample, degree earners are significantly more likely to be female, older, white, and less likely to be black or have children. They also have completed higher grades and are less likely to ever been arrested by baseline. Lastly, degree earners are less likely to have received public benefits by baseline and have better labor market outcomes at baseline: more likely to be employed and higher weekly earnings.

As for the other samples, the direction and statistical significance of their differences between degree earners and non-earners are very similar to those of the full sample, with some noteworthy exceptions across race and ethnic groups. Relative to the differences in the full sample, white degree earners are not significantly more likely to be employed and have higher earnings. In contrast, black degree earners are both more likely to be employed and have higher earnings. Hispanic degree earners are more likely to be employed, but do not significantly earn more. Across all races and ethnic groups there is no significant difference in arrest probabilities at baseline between degree earners and non-earners, although the former are significantly less likely to have been arrested by quarter 16. Finally, for each race/ethnicity, there is no significant difference between degree earners and non-earners in the likelihood of having received public benefits by baseline.

Overall, the differences in average baseline characteristics between degree earners and nonearners provide suggestive evidence of selection into degree attainment status, for each of the samples. The econometric approach employed uses randomization into JC as a source of exogenous variation to construct our bounds on the effect of degree attainment on arrests, thereby accounting for this selection. 


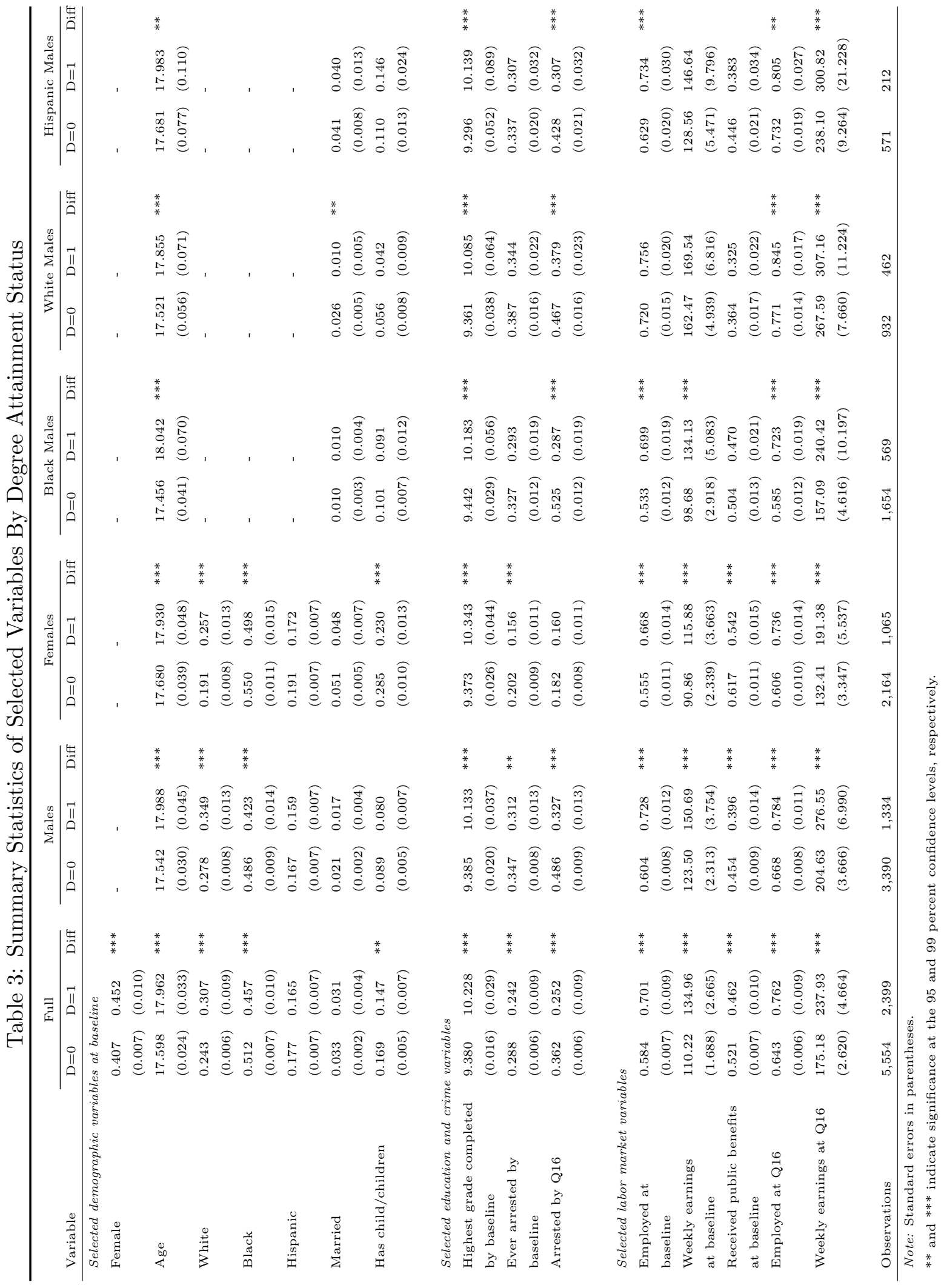




\section{Econometric Methods}

We analyze the effect of earning a degree on the probability of being arrested, using random assignment to JC under the NJCS as an instrumental variable (IV) for degree attainment. While random assignment to $\mathrm{JC}$ is exogenous (one of the assumptions of the IV estimator), it may not satisfy the exclusion restriction: there may be channels other than the attainment of a degree through which random assignment to JC impacts crime. For instance, random assignment can directly impact the incidence of arrests through the variety of other services offered by JC (e.g., counseling, social skills training). For this reason, we employ the nonparametric bounds in Flores and Flores-Lagunes (2013; hereafter FF-L), which allow the instrument to have a direct effect on arrests through channels other than earning a degree while exploiting its exogenous variation and strong effect on degree attainment. Indeed, FF-L (2013) discuss that their nonparametric bounds can be employed to estimate the effects of a non-randomized treatment (here degree attainment) by using as an IV a randomized variable from an unrelated existing experiment (here random assignment to JC). Since the original aim of the experiment being exploited was not to estimate the effects of the non-randomized treatment of interest, the exclusion restriction is unlikely to hold, which is the case in our current setting. ${ }^{9}$

Denote by $Z$ the random assignment into JC, with $Z=0$ if the eligible applicant was assigned to the control group and $Z=1$ if assigned to the treatment group. $Z$ will be used as the instrumental variable. $D$ denotes the binary indicator for degree attainment by quarter 8 after randomization (the treatment), with $D=1$ if a degree is attained and $D=0$ if not. Let $z$ and $d$ denote values of $Z$ and $D$, respectively. Since $D$ is affected by the instrument $Z$, we denote its potential values as $D(z)$, where $D(1)$ is the degree indicator if the individual were assigned to the treatment group, and $D(0)$ is the degree indicator if assigned to the control group. Following Imbens and Angrist (1994) and Angrist et al. (1996), we can partition the population into four (latent) principal strata based on the values of the vector $\{D(0), D(1)\}$ : "compliers" $(\{D(0)=0, D(1)=1\}$; earn a degree only if assigned to the treatment group), "always-takers" $(\{D(0)=1, D(1)=1\}$; earn a degree irrespective of $z)$, "never-takers" $(\{D(0)=0, D(1)=0\}$; do not earn a degree irrespective of $z)$, and "defiers" ( $\{D(0)=1, D(1)=0\}$; earn a degree only if not assigned to the treatment group). We refer to these principal strata as $c$, at, nt, and $d$ respectively.

\footnotetext{
${ }^{9}$ Besides relaxing the exclusion restriction assumption, there are other advantages to using these bounds in the current setting, such as their nonparametric nature, that they permit unrestricted heterogeneous treatment effects, and that they do not require a bounded outcome.
} 
The outcome - whether the individual was arrested over the 16 quarters after randomization — is denoted by $Y$. Denote the following four potential outcomes by $Y(z, D(z)): Y(1, D(1)) \equiv Y(1)$, $Y(0, D(0)) \equiv Y(0), Y(0, D(1))$, and $Y(1, D(0))$. The first two potential outcomes can be observed in the data (although never for the same individual), with the first corresponding to the outcome under exposure to the instrument (i.e., assignment to the treatment group) and the second to the outcome under no exposure to the instrument (i.e., assignment to the control group). They are related to the reduced-form average effect of the instrument on the outcome (i.e., $E[Y(1)-Y(0)])$. The last two potential outcomes are truly counterfactual outcomes because, in principle, they are never observed in the data. The third potential outcome represents the outcome under no exposure to the instrument but having the value of the treatment variable that the individual would have had under exposure to the instrument $(D(1))$. The last potential outcome represents the outcome under exposure to the instrument but blocking the effect of the instrument on treatment variable by keeping the latter fixed at its value under no exposure to the instrument $(D(0))$.

Some of the assumptions underlying the nonparametric bounds in FF-L (2013) overlap with those of the traditional IV estimator for causal effects, so it is instructive to start reviewing them in that context. At the same time, we offer justification for those assumptions in our current empirical context. Under heterogeneous effects, Imbens and Angrist (1994) and Angrist et al. (1996) show that the IV estimator point identifies the local average treatment effect for the compliers principal stratum, which can be defined as:

$$
L A T E_{c} \equiv E[Y(z, 1)-Y(z, 0) \mid D(1)-D(0)=1]
$$

The point identification result for $L A T E_{c}$ is achieved under the following assumptions: (A1) Random assignment of the instrument $Z$; (A2) Non-zero average effect of the instrument on the treatment $(E[D(1)-D(0)] \neq 0) ;(\mathrm{A} 3)$ Individual-level monotonicity of the instrument on the treatment $(D(1) \geq D(0)$ for all individuals), also known as the "no defiers" assumption since it rules out the defiers stratum. The last assumption in the traditional IV estimator, which will be disposed of in our nonparametric bounds, is the exclusion restriction (ER): the instrument has an effect on the outcome exclusively through the treatment $(Y(0, d)=Y(1, d)$ for all individuals $) .{ }^{10}$ Other important parameters besides $L A T E_{c}$ are point identified under (A1) to (A3), such as the proportion of individuals that belong to each of the principal strata $c$, at, and $n t$ (by combining

${ }^{10}$ In addition to these assumptions, the stable unit treatment value assumption (SUTVA) is also employed, which implies that there is no interference between individuals (i.e., their potential outcomes do not depend on the treatment status of other units) and that there are no different versions of the treatment (Rubin, 1980 and 1990). 
(A1) with (A3), which disposes of $d$ ). We denote these point-identified proportions by $\pi_{k}$, with $k \in\{c, a t, n t\}$. Furthermore, using these identified proportions one can estimate average values of pre-treatment variables for each stratum (e.g., Chen and Flores, 2015), which we will use below to offer support for one of our additional assumptions.

We believe that assumptions (A1) to (A3) are likely satisfied in our context. (A1) is satisfied by design since we employ random assignment into JC as our instrumental variable; similarly, (A2) is satisfied given the previously documented strong and statistically significant average effect of random assignment into JC on degree attainment. (A3) implies that there are no individuals that would not attain a degree if assigned to JC but would attain a degree if not assigned to JC. Given that JC's aim is to facilitate earning a degree through subsidized training in an environment conducive to that end, (A3) is plausibly satisfied - although we recognize that this IV assumption is often criticized for requiring that all individuals in the sample satisfy such monotonicity.

Given that the exclusion restriction (ER) is likely not satisfied in our context, we drop this assumption and estimate nonparametric bounds on a local average treatment effect $(L A T E)$. FF-L (2013) show that, in the IV setting above, the exclusion restriction can be discarded by allowing the instrument to have a direct (or net) effect on the outcome in addition to the indirect (or mechanism) effect that works through the treatment. In other words, these two effects conceptually decompose the total average effect of the instrument (assignment to JC) on the outcome (arrests) into two parts: a part that works through the treatment (degree attainment) — the average mechanism effect — and a part that works through the rest of the channels (e.g., counseling and health services) - the average net effect. FF-L (2013) relate the mechanism effect to a LATE parameter for compliers. Using this relation and the bounds on mechanism effects in FF-L (2010), bounds can be constructed on that $L A T E$.

More formally, consider the reduced-form average effect (or intention-to-treat effect) of the instrument $(Z)$ on the outcome $(Y)$, denoted by $A T E_{Z Y} \equiv E[Y(1)-Y(0)]$, which can be decomposed into two average effects (FF-L, 2010): MATE $\equiv E[Y(1)-Y(1, D(0))]$ and $N A T E \equiv$ $E[Y(1, D(0))-Y(0)]$. The first is the mechanism average treatment effect (MATE) and represents the effect of $Z$ working through the "mechanism" $D$ (note how $D(z)$ changes from $D(0)$ to $D(1)$ ). The second effect is the net average treatment effect (NATE) since it represents the effect of $Z$ on $Y$ "net" of $D$, that is, the "direct" effect of the instrument on the outcome. ${ }^{11}$ Importantly, under

\footnotetext{
${ }^{11}$ Note that in $N A T E$ the value of $Z$ changes while holding constant the value of the mechanism at $D(0)$. A similar
} decomposition can be achieved while holding $D(1)$ constant. See FF-L (2013) for more discussion on this feature. 
the (ER) assumption $N A T E=0$ (since the direct effect is assumed to be zero), but when (ER) is dropped both $M A T E$ and $N A T E$ can be non-zero. Also note that MATE intuitively reflects the desired exogenous impact on the treatment brought about by the instrument with which to identify a treatment effect of interest. Indeed, FF-L (2013) show that MATE can be related to the following local average treatment effect for compliers:

$$
L A T E \equiv E[Y(1)-Y(1,0) \mid D(1)-D(0)=1]=M A T E /\{E[D(1)-D(0)]\}
$$

In our current context, $L A T E$ gives the effect of attaining a degree on the probability of being arrested for compliers, under assignment to JC (i.e., under $z=1$ ). ${ }^{12}$

The importance of relating $M A T E$ to $L A T E$ is that one can use the bounds proposed in FF-L (2010) for $M A T E$ to bound $L A T E$, since the term $E[D(1)-D(0)]$ is point identified under (A1). To construct bounds on $M A T E$, the approach taken by FF-L (2010) is to first construct bounds on the "local" versions of $N A T E$ and MATE for each stratum, denoted by $L N A T E_{k}$ and $L M A T E_{k}$ and defined in an analogous way conditioning on the corresponding stratum (e.g., $L N A T E_{a t}=$ $E[Y(1, D(0))-Y(0) \mid a t]$ ). Subsequently, bounds on $M A T E$ (and $N A T E$ ) can be obtained by aggregation to the population level, since the proportion of each stratum is point identified. FFL $(2010,2013)$ show that under (A1) to (A3) only $L N A T E_{n t}$ and $L N A T E_{a t}$ can be bounded by using "trimming bounds" (Lee, 2009; Zhang et al., 2008), since the counterfactual outcome $Y(1, D(0))$ is never observed for compliers. ${ }^{13}$ Therefore, additional assumptions are required in order to construct nonparametric bounds on the population-level MATE, NATE, and the LATE in (1) while disposing of the (ER) assumption. Intuitively, these additional assumptions will relate the remaining unidentified conditional expectation $E[Y(1, D(0)) \mid c]$ to at least one of those that are point-or partially-identified under (A1) to (A3).

FF-L (2010, 2013) consider two additional assumptions (besides (A1)-(A3)) that involve weak

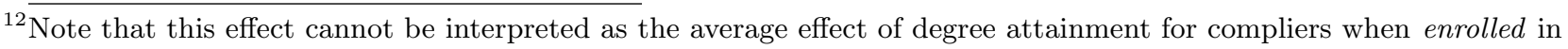
JC due to the noncompliance present in the NJCS. In addition, the compliers are those who attain a degree only if assigned to participate (rather than enrolled) in JC. This subtle difference in the interpretation of our parameter of interest is the only consequence of the noncompliance issue in the NJCS.

${ }^{13} \mathrm{It}$ is important to note that for $n t$ and at $Y(1, D(0))=Y(1)\left(\right.$ and $\left.L M A T E_{n t}=L M A T E_{a t}=0\right)$, since $D(0)=D(1)$ for these two strata. Hence, for each one of $L N A T E_{n t}$ and $L N A T E_{a t}$, one conditional expectation is point identified $(E[Y(1) \mid n t]$ and $E[Y(0) \mid a t]$, respectively) while the other expectation is not because $c$ are mixed with $n t$ or at, respectively, in the corresponding random assignment arm. However, they can be bounded using a trimming procedure given that the strata proportions are point identified. Other conditional expectations that can be bounded with the same trimming procedure are $E[Y(1) \mid c]$ and $E[Y(0) \mid c]$. See FF-L (2013) for more details. 
monotonicity of mean potential outcomes at the principal stratum level: ${ }^{14}$

\section{Assumption 4 (Weak Monotonicity of Mean Potential Outcomes Within Strata)}

(a) $E[Y(1) \mid c] \leq E[Y(1, D(0)) \mid c]$ and

(b) $E[Y(1, D(0)) \mid k] \leq E[Y(0) \mid k]$, for $k=n t$, at, c.

and,

Assumption 5 (Weak Monotonicity of Mean Potential Outcomes Across Strata)

(a) $E[Y(1, D(0)) \mid c] \leq E[Y(1) \mid n t] ; \quad$ (b) $E[Y(1) \mid a t] \leq E[Y(1, D(0)) \mid c]$,

(c) $E[Y(0) \mid c)] \leq E[Y(0) \mid n t] ; \quad$ (d) $E[Y(0) \mid a t] \leq E[Y(0) \mid c]$

(e) $E[Y(1) \mid c] \leq E[Y(1) \mid n t] ; \quad$ (f) $E[Y(1) \mid a t] \leq E[Y(1) \mid c]$.

In our context, (A4) posits that the attainment of a degree has an average non-positive effect on the incidence of arrests for compliers (part (a)); and that the average net effect of random assignment on the incidence of arrests (i.e., the average effect of assignment to JC on arrests through channels other than degree attainment) is non-positive for each stratum (part (b)). The overall characteristics of the JC program argue in favor of (A4), as they are intended to improve participants' labor market outcomes and well-being (e.g., through its residential nature, health services, and counseling), all of which are predicted to have a non-positive average effect on arrests. It is also worthy of note that (A4) concerns weak monotonicity of average outcomes, which allows certain individuals to violate the weak monotonicity conditions on their potential outcomes. As long as the average over all individuals belonging to a given stratum does not violate the weak monotonicity conditions, then (A4) still holds.

In turn, (A5) formalizes the notion that always-takers likely have no worse average potential outcomes (i.e., no higher arrest incidence) than compliers, which in turn have no worse average potential outcomes than never-takers. Intuitively, the "no worse" strata have more favorable characteristics that lead to (weakly) better mean potential outcomes. For this assumption, we can gather indirect evidence that the proposed ranking of strata is plausible by comparing pretreatment arrest rates across the three strata. Table 4 shows the pre-treatment arrest rates for all

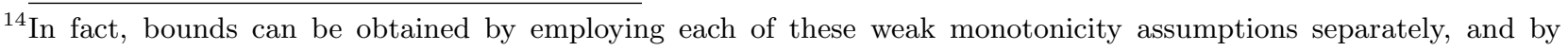
combining them. For brevity, most of the estimated bounds we discuss and present use both assumptions since they produce the tightest bounds and we do not find empirical evidence against them (except suggestive evidence against (A5) for Hispanics), as discussed below. 
of our subgroups. We see that the three strata are weakly ranked by their pre-treatment arrest rates in the way posited by (A5) — with some pairwise differences being statistically significantfor all subgroups analyzed, except for Hispanics. For Hispanics, compliers have an unusually low pre-treatment arrest rate relative to that of always-takers, which makes the difference statistically significant. Although this does not directly imply that (A5) is violated for Hispanic males since the means are for pre-treatment rather than potential outcomes, it raises doubt on the validity of (A5) for this demographic group. This is the only instance of a statistically significant (suggestive) violation of the posited strata weak ranking among the six samples considered.

Table 4: Pre-Treatment Arrest Rates by Principal Strata

\begin{tabular}{lcccccc}
\hline & $n t$ & $c$ & $a t$ & $n t-c$ & $c-a t$ & $n t-a t$ \\
\hline Full Sample & $0.291^{* * *}$ & $0.284^{* * *}$ & $0.243^{* * *}$ & 0.007 & $0.042^{*}$ & $0.049^{* *}$ \\
& $(0.009)$ & $(0.014)$ & $(0.019)$ & $(0.016)$ & $(0.023)$ & $(0.021)$ \\
Males & $0.353^{* * *}$ & $0.322^{* * *}$ & $0.304^{* * *}$ & 0.031 & 0.017 & $0.049^{*}$ \\
& $(0.013)$ & $(0.018)$ & $(0.026)$ & $(0.022)$ & $(0.032)$ & $(0.029)$ \\
Females & $0.202^{* * *}$ & $0.209^{* * *}$ & $0.150^{* * *}$ & -0.007 & $0.060^{*}$ & $0.053^{*}$ \\
& $(0.012)$ & $(0.016)$ & $(0.020)$ & $(0.020)$ & $(0.029)$ & $(0.024)$ \\
Black Males & $0.326^{* * *}$ & $0.353^{* * *}$ & $0.256^{* * *}$ & -0.027 & $0.097^{* *}$ & $0.070^{*}$ \\
& $(0.016)$ & $(0.025)$ & $(0.035)$ & $(0.030)$ & $(0.043)$ & $(0.038)$ \\
White Males & $0.412^{* * *}$ & $0.291^{* * *}$ & $0.343^{* * *}$ & $0.121^{* * *}$ & -0.052 & 0.069 \\
& $(0.023)$ & $(0.029)$ & $(0.041)$ & $(0.037)$ & $(0.050)$ & $(0.049)$ \\
Hispanic Males & $0.365^{* * *}$ & $0.155^{* * *}$ & $0.344^{* * *}$ & $0.210^{* * *}$ & $-0.189^{* * *}$ & 0.021 \\
& $(0.028)$ & $(0.033)$ & $(0.059)$ & $(0.043)$ & $(0.068)$ & $(0.066)$ \\
\hline
\end{tabular}

Notes: Standard errors in parentheses. ${ }^{*},{ }^{* *}$, and ${ }^{* * *}$ indicate significance at the 90,95 , and 99 percent confidence levels, respectively.

In addition to the indirect evidence for (A5) presented above, the combination of (A1) to (A5) provides three testable implications that can be used to falsify them (FF-L, 2013). While satisfying these testable implications in the data does not guarantee that the assumptions hold, finding that they do not hold in the data is a clear indication that some of the assumptions are not satisfied. Table 5 provides the results of the testable implications (their expressions listed in the first column) for all samples analyzed. The testable implications are not statistically rejected in our data for any sample. In summary, we do not find evidence against the validity of (A1) to (A5), with the exception of some indirect evidence suggesting the possible invalidity of (A5) for Hispanics. Thus, we employ the nonparametric bounds previously described under assumptions (A1) to (A5). The formal expressions of the bounds are not reproduced here to conserve space since they can be found in FF-L (2013).

A final note pertains to the estimation of the nonparametric bounds and the construction of 
Table 5: Testable Implications of Assumptions (A1) to (A5)

\begin{tabular}{|c|c|c|c|c|c|c|}
\hline & Full & Males & Females & Black Males & White Males & Hispanic Males \\
\hline $\mathrm{E}[Y \mid Z=0, D=1]-\mathrm{E}[Y \mid Z=0, D=0] \leq 0$ & $\begin{array}{c}-0.118^{* * *} \\
(0.022)\end{array}$ & $\begin{array}{c}-0.183^{* * *} \\
(0.029)\end{array}$ & $\begin{array}{l}-0.002 \\
(0.033)\end{array}$ & $\begin{array}{c}-0.281^{* * *} \\
(0.038)\end{array}$ & $\begin{array}{l}-0.055 \\
(0.049)\end{array}$ & $\begin{array}{l}-0.102 \\
(0.064)\end{array}$ \\
\hline $\mathrm{E}[Y \mid Z=1, D=1]-\mathrm{E}[Y \mid Z=1, D=0] \leq 0$ & $\begin{array}{c}-0.110^{* * *} \\
(0.015)\end{array}$ & $\begin{array}{c}-0.146^{* * *} \\
(0.021)\end{array}$ & $\begin{array}{l}-0.037^{*} \\
(0.019)\end{array}$ & $\begin{array}{c}-0.204^{* * * *} \\
(0.029)\end{array}$ & $\begin{array}{c}-0.106^{* * *} \\
(0.035)\end{array}$ & $\begin{array}{c}-0.154^{* * *} \\
(0.048)\end{array}$ \\
\hline $\mathrm{E}[Y \mid Z=1, D=1]-\mathrm{E}[Y \mid Z=0, D=0] \leq 0$ & $\begin{array}{c}-0.129^{* * *} \\
(0.016)\end{array}$ & $\begin{array}{c}-0.182^{* * *} \\
(0.022)\end{array}$ & $\begin{array}{l}-0.036^{*} \\
(0.021)\end{array}$ & $\begin{array}{c}-0.236^{* * *} \\
(0.029)\end{array}$ & $\begin{array}{c}-0.113^{* * *} \\
(0.035)\end{array}$ & $\begin{array}{l}-0.089^{*} \\
(0.048)\end{array}$ \\
\hline
\end{tabular}

valid confidence intervals. The nonparametric bounds discussed above are functions of conditional expectations, sometimes computed over trimmed distributions, which are all easy to estimate. However, some of the bounds involve minimum (min) and maximum (max) operators over several conditional expectations, which create complications for standard estimation and inference. The concavity and convexity of the min and max functions, respectively, can bias the estimates of the bounds, causing them to be narrower than the true bounds. Additionally, the asymptotic distribution of estimators for parameters involving min and max functions is usually unavailable. Furthermore, Hirano and Porter (2012) show that there exist no locally asymptotically unbiased estimators and no regular estimators for parameters involving min or max operators. In order to obtain valid estimates and perform statistical inference in the next section, we employ a method proposed by Chernozhukov, Lee, and Rosen (2013; hereafter CLR). The CLR methodology allows us to obtain half-median unbiased estimators for our lower and upper bounds, as well as valid confidence intervals for the true parameter values. ${ }^{15}$ For more details on the CLR methodology, we refer the reader to CLR (2013), and for our particular implementation of the method to FF-L (2013). For the bounds without min or max operators, we compute plug-in estimates of the bounds and confidence intervals for the true parameters based on Imbens and Manski (2004).

\section{Results}

Table 6 presents, for each sample, point estimates of a number of relevant parameters as well as a set of estimated nonparametric bounds on the net average treatment effect $(N A T E)$ and the mechanism average treatment effect $(M A T E)$ of random assignment on the probability of being arrested, considering degree attainment as the mechanism of interest. The estimated bounds on

\footnotetext{
${ }^{15}$ The half-median-unbiasedness property means that the upper (lower) bound estimator exceeds (falls below) the true value of the upper (lower) bound with probability at least one half asymptotically.
} 
$N A T E$ are informative about the potential violation of the ER assumption, while those on $M A T E$ give a preliminary idea about the bounds on $L A T E$, as the bounds on $L A T E$ equal the bounds on $M A T E$ divided by the first-stage average effect of random assignment on degree attainment (see equation (1)). The first row in Table 6 provides the point estimate of the average effect of randomization into $\mathrm{JC}$ (the instrument) on arrests, denoted as $A T E_{Z Y}$ in the previous section. This is the effect that is decomposed into the direct and indirect effects (NATE and MATE, respectively), and the latter is the basis for the estimation of bounds on the LATE on arrests without imposing the ER assumption. Consistent with the findings in the NJCS (Schochet et al. 2001 and Schochet et al. 2008), the average effect of randomization into JC on arrests is a significant reduction of 3 percentage points for the full sample (a reduction of $8.7 \%$ with respect to the control group arrest rate). There is some heterogeneity across samples, with males and whites experiencing a similar reduction to that of the full sample (both 0.038), and blacks having a much higher reduction of 0.053. In contrast, this effect is statistically insignificant for females at -0.015 and positive and statistically insignificant for Hispanics at 0.31 . As mentioned before, and as reported in the literature analyzing the NJCS data (e.g., Schochet et al., 2001; Schochet et al., 2008; Flores-Lagunes et al., 2010; Blanco et al., 2013), Hispanics in the NJCS often exhibit imprecisely estimated effects, likely as a result of being a fairly heterogeneous group.

The second row in Table 6 presents point estimates of the average effect of randomization into JC on degree attainment by quarter 8 . Across all samples, this effect is positive and highly statistically significant, which speaks to the validity of (A2). The magnitude of this effect for the full sample is 0.165 , which represents an increase of $80 \%$ relative to the control group degree attainment rate, and it is fairly consistent across samples. This increase stands in contrast with the typical effect of CSL on degree attainment of 3 to $5 \%$. The third row shows point estimates of the $L A T E_{c}$ of degree attainment on arrests that impose the ER assumption, which requires that all the effect of JC randomization on arrests works through the attainment of a degree. This effect is estimated as highly statistically significant for the full sample $(-0.18)$, males $(-0.236)$, and blacks $(-0.33)$; while it is not statistically significant for whites $(-0.212)$ and females $(-0.093)$, and it is positive and insignificant for Hispanics (0.201). The statistically significant $L A T E_{c}$ effects are large relative to the estimates obtained in the CSL literature, and they fall outside our estimated bounds and their $95 \%$ confidence intervals to be reported below. 


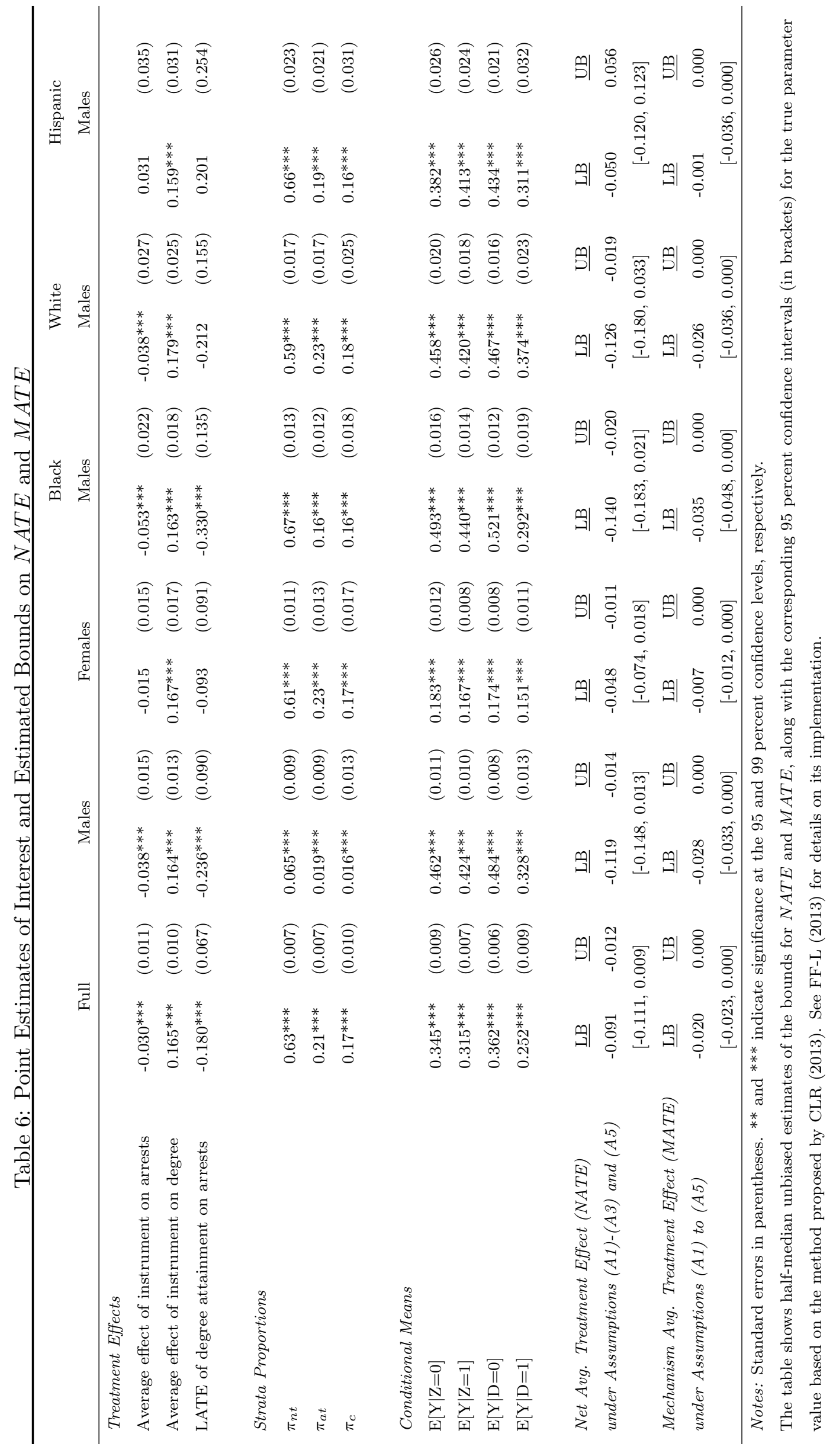


The second panel in Table 6 reports point estimates of the strata proportions of never-takers, always-takers, and compliers, which are point-identified under (A1) to (A3). All estimated proportions are highly statistically significant and are fairly consistent across samples. For the full sample, the proportion of never-takers is estimated at $63 \%$, that of always-takers at $21 \%$, and that of compliers at $17 \%$. The following panel in the table provides, for reference, point estimates of the outcome (arrest rates between baseline and quarter 16) for four different groups given by random assignment status and by degree attainment status. Comparing the conditional means by degree status yields an estimate of the effect of degree attainment on arrests that does not control for selection in any way and thus is likely (upward) biased for the effect of degree attainment on crime, as suggested by the evidence discussed surrounding Table 3 .

The next-to-last panel of Table 6 presents statistical evidence of the likelihood that the ER is violated in this application. In particular, it shows estimated bounds on NATE - the net (of degree attainment) effect of randomization into $\mathrm{JC}$ on arrest rates. Importantly, these bounds were estimated without assumption (A4) in order not to impose an assumption about the sign of this effect - even though we did not find evidence against this assumption in the previous sectionresulting in more conservative inference towards the ER. The table shows that the estimated bounds on NATE contain only negative values and rule out zero (except for Hispanics, which are consistent with either positive or negative values). Unfortunately, the $95 \%$ confidence intervals on the bounds are not able to rule out a zero $N A T E$, often marginally. ${ }^{16}$ Overall, we interpret this evidence as strongly suggesting that the ER assumption is likely not satisfied in this application.

The final panel of Table 6 presents estimated bounds on MATE under assumptions (A1) to (A5). They are the basis for the bounds on the LATE of degree attainment on arrests since MATE represents the exogenous change in degree attainment due to random assignment. All estimated bounds on MATE are non-positive (as implied by the assumptions) and their lower bound is a fraction of the corresponding average effect of the instrument on arrests $\left(A T E_{Z Y}\right)$. Indeed, given the decomposition of $A T E_{Z Y}$ into $M A T E$ and $N A T E$, the lower bounds can be interpreted as the largest portion of the average effect of the instrument on arrests that works through the attainment of a degree. In percentage terms (and excluding Hispanics), the attainment of a degree represents

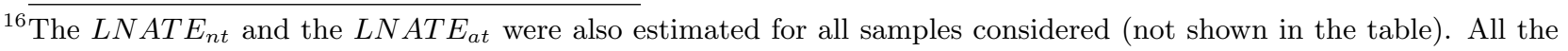
estimated bounds exclude zero (except for Hispanics, and for the $L N A T E_{a t}$ for males and black males). Similar to the case of NATE, the $95 \%$ confidence intervals on these bounds are not able to rule out a zero effect, often marginally. 
at most from $46.7 \%$ (for females) to $73.7 \%$ (for males) of the total effect of the instrument on arrests. ${ }^{17}$ For Hispanics, it is hard to interpret their lower bound on MATE in his way, since $A T E_{Z Y}$ for this group is positive, albeit statistically insignificant.

Table 7 presents the main results: nonparametric bounds for the LATE of degree attainment by quarter 8 after randomization on the incidence of arrests between randomization and quarters 16, under assumptions (A1)-(A5). These estimated bounds allow for the violation of the ER assumption, and at the same time control for selection into degree attainment by exploiting the exogenous variation given by the random assignment. The estimated bounds for all groups are non-positive, as implied by our assumptions. For the full sample, the estimated lower bound is -11.8 percentage points, which represents an effect of $-32.6 \%$ relative to the percentage of individuals arrested in the no-degree-attainment "control" group (presented in the previous to last column). Thus, negative effects larger than that (or $-38.3 \%$ based on the $95 \%$ confidence interval) can be ruled out. ${ }^{18}$ This information is relevant for policy purposes. For example, if JC administrators were to take the necessary steps to increase the effect of JC on degree attainment to 0.50 , then, ceteris paribus, JC can be expected to reduce the probability of being arrested by at most $(0.50)(0.118)=0.059$, or about $17 \% .^{19}$

All of the point estimates of the effect of education on crime in Section 1 fall within our bounds for the full sample. Remarkably, even though we use a very different source of exogenous variation and methods, our results are very similar to those found using CSLs when comparing $95 \%$ confidence intervals (CI) covering the true effect of education on crime. We interpret this as evidence that our results, as well as those from using CSLs, may indeed be capturing a true causal effect of education on crime. The $95 \%$ CI for the percentage effect of one additional year of schooling on arrest rates in LM $(2004)$ is $[-32.5 \%, 2.6 \%]$ for males, which is very close to our

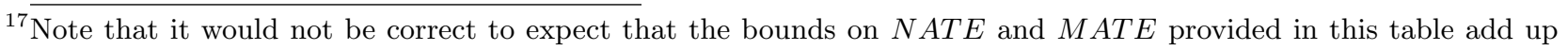
to the $A T E_{Z Y}$. The reason is that they are employing slightly different assumptions. If one looks at the $N A T E$ bounds under (A1) to (A5) — which are not shown in the table - they do add up to the $A T E_{Z Y}$, aside from finite sample corrections performed through the CLR (2013) procedure.

${ }^{18} \mathrm{It}$ is interesting to relate the results for the full sample to the point-estimated effects of random assignment and participation in JC on arrests in the NJCS. As reported in section 2.2, the percentage reduction in arrests from random assignment (the $A T E_{Z Y}$ or intention-to-treat) is $11.35 \%$, while the corresponding percentage reduction per participant in JC is $15.8 \%$. Clearly, both estimates fall within our estimated bounds for the LATE of degree attainment on arrests. It is important to keep in mind, however, that each of these estimates is for a different treatment and population.

${ }^{19}$ Clearly, just as it is the case in studies estimating a LATE, this type of calculations rely on linear extrapolations. 
Table 7: Bounds on the Local Average Treatment Effect of Attaining a Degree on the Incidence of Arrest

\begin{tabular}{|c|c|c|c|c|}
\hline & $\begin{array}{l}\text { Lower } \\
\text { Bound }\end{array}$ & $\begin{array}{l}\text { Upper } \\
\text { Bound }\end{array}$ & $\begin{array}{c}\text { Percentage } \\
\text { Arrested } \\
\text { in "Control"a }\end{array}$ & $\begin{array}{c}\text { Largest } \\
\text { Percentage } \\
\text { Effect }\end{array}$ \\
\hline Full Sample & $\begin{array}{c}-0.118 \\
{[-0.139}\end{array}$ & $\begin{array}{r}0.000 \\
0.000]\end{array}$ & 36.23 & -32.60 \\
\hline Males & $\begin{array}{c}-0.165 \\
{[-0.193}\end{array}$ & $\begin{array}{r}0.000 \\
0.000]\end{array}$ & 48.64 & -33.95 \\
\hline Females & $\begin{array}{c}-0.043 \\
{[-0.069}\end{array}$ & $\begin{array}{r}0.000 \\
0.000\end{array}$ & 18.16 & -23.63 \\
\hline Black Males & $\begin{array}{c}-0.214 \\
{[-0.280}\end{array}$ & $\begin{array}{r}0.000 \\
0.000]\end{array}$ & 52.45 & -40.80 \\
\hline White Males & $\begin{array}{c}-0.139 \\
{[-0.196}\end{array}$ & $\begin{array}{r}0.000 \\
0.000]\end{array}$ & 46.73 & -31.48 \\
\hline Hispanic Males & $\begin{array}{c}-0.021 \\
{[-0.213}\end{array}$ & $\begin{array}{r}0.000 \\
0.000]\end{array}$ & 42.82 & -4.91 \\
\hline \multicolumn{5}{|c|}{$\begin{array}{l}\text { a "Control" refers to the group of individuals not attaining a degree. } \\
\text { Note: The table shows half-median unbiased estimates of the bounds } \\
\text { and } 95 \text { percent confidence intervals (in brackets) for the true parameter } \\
\text { value based on the method proposed by CLR (2013). See FF-L (2013) for } \\
\text { details on its implementation. }\end{array}$} \\
\hline
\end{tabular}

95\% CI for males of $[-39.7 \%, 0.0 \%]{ }^{20}$ Moreover, the average number of hours of academic and vocational instruction received while enrolled in $\mathrm{JC}$ for those individuals who participated and obtained a degree is 1,448. Considering that a typical high school student receives the equivalent of 1,080 hours of instruction during the school year (Schochet et al., 2001), obtaining a degree in JC is comparable to 1.34 years of schooling. Thus, our results for males suggest a $95 \% \mathrm{CI}$ on the effect of a one-year increase in schooling on the probability of being arrested of about $[-29.6 \%, 0.0 \%]$ (dividing by 1.34), which is slightly tighter than the one in LM (2004). The 95\% CI corresponding to the other estimates discussed in Section 1 are: $[-34.3 \%, 0.3 \%]$ in Anderson (2014); [-14\%, 0.5\%] in Hjalmarsson, Holmlund, and Lindquist (2014); and [-35.5\%, $-0.07 \%]$ in Machin, Marie, and Vujić (2011). ${ }^{21}$

Comparing the results by gender, the estimated lower bound on the percentage-point effect for males is about four times that of females. Since females have considerably lower arrest rates than males, the estimated lower bound on their percentage effect is somewhat closer to that of males (23.63\% vs. $33.95 \%)$. This is in line with U.S. evidence from Anderson (2014), where percentage

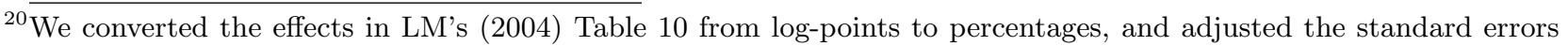
using the delta method.

${ }^{21}$ The confidence intervals are based on percentage effects calculated from the following estimates: -10.27 in Anderson (2014) column 3, Table 4; -0.022 in Hjalmarrson, Holmlund, and Lindquist (2015) column 4, Table 5; -0.212 in Machin Marie, and Vujić (2011), column 5, Table 2. 
effects of CSLs on arrest rates for men are 17\%, and a statistically insignificant $10.5 \%$ for females. In turning to the results by race/ethnicity, while there is a large degree of overlap among their bounds, there are marked differences in the estimated lower bounds and largest percentage effects for black, white, and Hispanic males. For black and white males, the lower bound shows that there is, respectively, at most, a 21.4 and 13.9 percentage-point reduction in the arrest rate due to the attainment of a degree. These lower bounds are related to a largest percentage effect of $-40.80 \%$ and $-29.74 \%$, respectively. The corresponding lower bound on the LATE for Hispanic males is -0.21 , implying that, at most, degree attainment reduces their arrests by only $4.91 \%$. In line with the previous discussions about Hispanics in the NJCS data, their estimated bounds are very imprecisely estimated (at least relative to the other samples). Lastly, while it is not possible to conclude from these results that the effect is larger for blacks than whites (or even Hispanics), the fact that the estimated lower bound is much larger (in absolute value) for blacks than for whites is consistent with the finding in LM (2004) that the effect of schooling on crime reduction is larger for blacks.

Table 8 presents nonparametric bounds estimates on $L A T E$ of degree attainment on arrests under assumptions (A1)-(A5). Each vertical panel shows the bounds estimates for a different specification of either the treatment or the outcome variable. The first three vertical panels break down the degree attainment variable into individuals that earn at least each one of its components in turn: high school (HS), general educational development (GED), and vocational (VOC) degree. We explore the potential heterogeneity of the results along this dimension given the widely documented non-equivalency of HS and GED degrees in what pertains to their financial returns (e.g., Heckman and LaFontaine, 2006, 2010). ${ }^{22}$ It is important to keep two points in mind. The first is that the sample sizes become smaller when considering the attainment of at least one particular type of degree. ${ }^{23}$ In fact, we had difficulty obtaining sensible estimates of the bounds for Hispanics, the smallest group of the six. The second is that, just as it was the case with the bounds for the race and ethnic groups, the bounds across types of degrees largely overlap with each other. As a result, we resort to providing a suggestive comparison based on the largest percentage effect computed

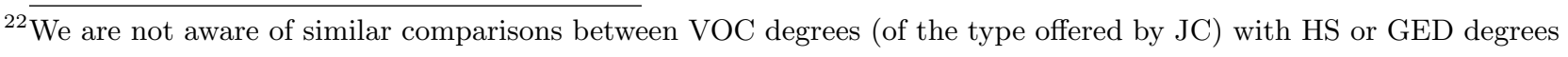
in terms of their financial returns. However, studies using the NJCS typically report that the effect of JC on weekly earnings is similar to the effect of one year of regular high school (e.g., Schochet et al., 2001; Flores et al., 2012).

${ }^{23} \mathrm{We}$ considered defining the degree attainment variables to reflect only the attainment of a given degree, but the resulting sample sizes are considerably small. This is due to the fact that, within JC, the typical student achieves more than one degree.
} 
based on the lower bound and the percentage of arrests in the corresponding control groups, as in Table 7.

The first vertical panel reports estimated bounds for the $L A T E$ of HS degree attainment. For the full sample, the largest percentage effect from HS attainment is a reduction in arrests that is almost 60 percent higher than the one reported in Table 7 (for any degree type). For the other groups, the largest percentage effect from HS attainment is similarly larger relative to any degree type. Conversely, the estimated bounds for the LATE of GED degree attainment have the largest percentage effects that are fairly similar to the results from any degree attained. ${ }^{24}$ The third vertical panel presents estimated bounds for the $L A T E$ of VOC degree attainment, which have the largest percentage effects that are in between those of HS and any degree attainment. ${ }^{25}$ Thus, there seems to be some suggestive evidence that the arrest reducing effects of degree attainment are largest for HS degree, followed by VOC and GED degrees, although we remark that the estimated bounds on the effects from different degrees attained largely overlap.

\footnotetext{
${ }^{24}$ The exception is females, for whom the largest percentage effect from GED is about half of that for any degree attained.

${ }^{25}$ The exception is again females, whose largest percentage effect from VOC is about the same as that for any degree attained.
} 


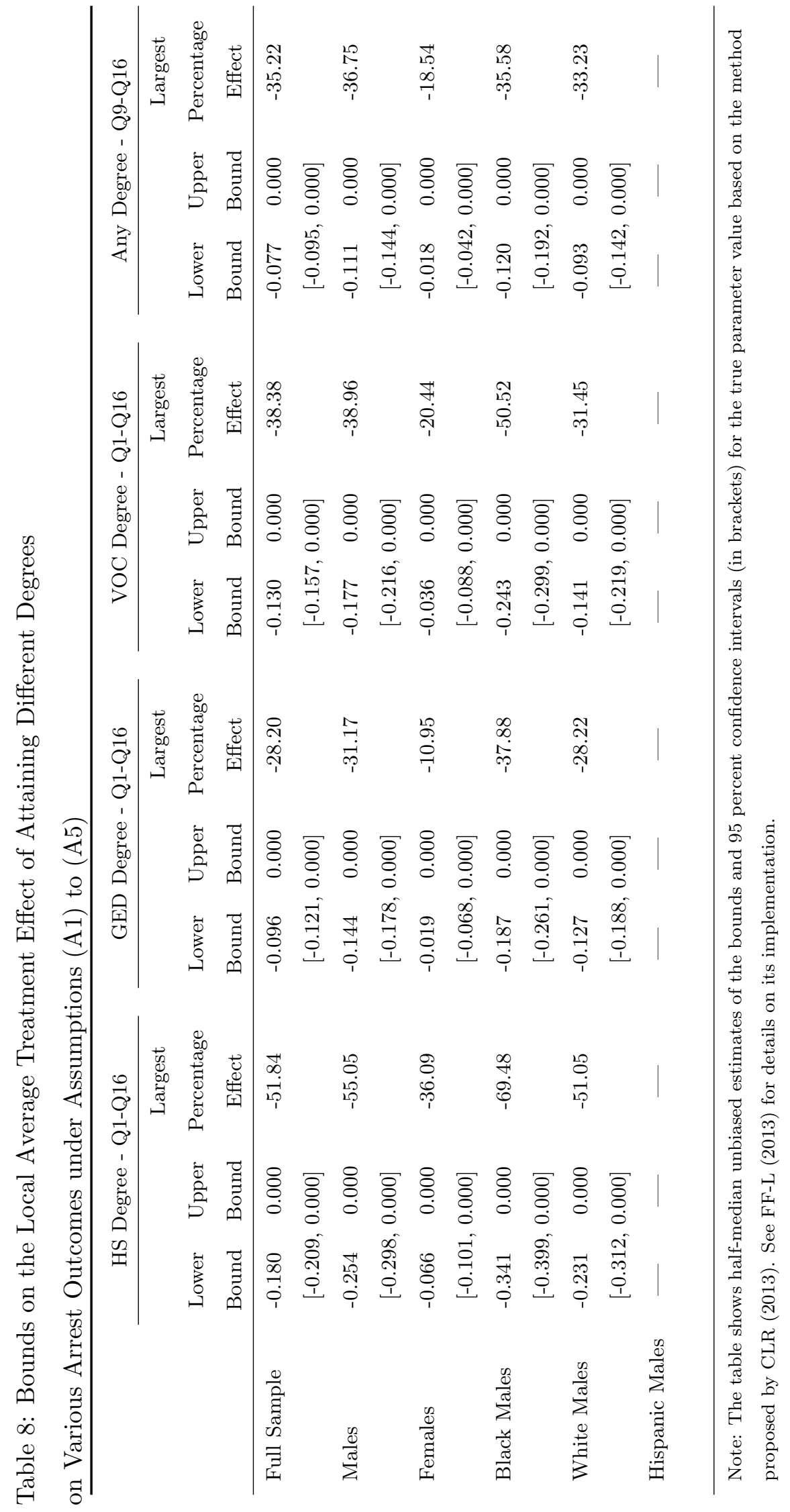


The last vertical panel of Table 8 presents estimated bounds for any degree attained redefining the outcome to be measured as arrests between quarters 9 and 16, instead of during all 16 quarters after randomization. The reason to consider this alternative measurement of the outcome is to indirectly address potential concerns of "reverse causality", as discussed in section 2.3. More specifically, while in our baseline results the measurement of the outcome overlaps in timing with the measurement of the attainment of the degree, in the current analysis the measurement of the treatment precedes that of the outcome. One of the reasons for not employing the current definition of the outcome as the baseline measure is that considering only a two year window after degree attainment, it results in a relatively small proportions of arrests, and a correspondingly small effect of randomization on arrests. ${ }^{26}$ Looking at the estimated bounds on the percentage-point effects, it is evident that they largely overlap with the bounds in Table 7, while the lower bounds are smaller in absolute value. However, when we consider the largest percentage effects that take into consideration the lower arrest incidence in the two last years of the NJCS, they are very similar to the baseline results in Table 7 . We interpret this similarity in results as suggestive evidence that the baseline results are not being driven by "reverse causality", that is, by the occurrence of arrests that prevent the attainment of a degree.

\section{Conclusion}

We analyze the causal effect of attaining a high school, GED, or vocational degree on arrests, focusing on a nationally representative group of disadvantaged youth in the U.S. A number of recent studies analyzing the causal effect of education on crime have employed changes in compulsory schooling laws - a natural experiment - as an instrumental variable for educational attainment. We employ the randomization into the Job Corps program within the National Job Corps Study as a source of exogenous variability in educational attainment. Instead of employing traditional instrumental variables estimators, we construct bounds on the causal effect of interest under relatively weak assumptions that do not require the exclusion restriction (the instrument having an impact on crime only through educational attainment) to hold.

Our main finding is that, despite the different assumptions, methods, and source of exogenous variation we exploit, our results are fairly consistent with the previous estimates of the causal effect

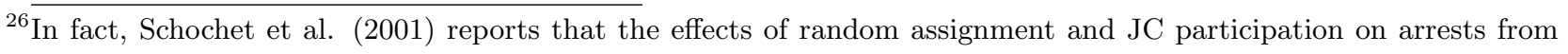
quarter 9 to 16 are much smaller than those from randomization to quarter 8 . They interpret this as evidence that the incapacitation effect of the JC program on arrests is significant. 
of education on crime based on compulsory schooling laws. We interpret this as suggestive evidence that our estimated bounds and the results of those studies indeed capture a true causal effect of education on crime. However, further research is needed since, unfortunately, our estimated bounds and the $95 \%$ confidence intervals in studies using compulsory schooling laws remain relatively wide, and in many cases are not able to exclude a zero effect. This is particularly the case for females because their arrest rates - and very likely also their effects - are substantially lower than those of males. The heterogeneity in our estimated lower bounds for blacks, whites, and Hispanics suggests that there may be considerable differences in the effect of education on arrest rates among these groups. Similarly, based on the heterogeneity in our estimated lower bounds for the effects of different types of degrees attained (high school, GED, and vocational), there is suggestive evidence that the attainment of a high school degree may have higher arrest-reducing effects, followed by vocational and GED degrees. Taking at face value the suggestive results on the arrest effects of the attainment of different degrees, along with the evidence on the larger financial returns of a high school degree relative to a GED degree (Heckman and LaFontaine, 2006, 2010), a case could be made for modifying the Job Corps program to de-emphasize the attainment of GED in favor of high school degrees.

Lastly, our analysis illustrates the implementation of the nonparametric bounds for local average treatment effects using an invalid instrumental variable developed in Flores and Flores-Lagunes (2013). A particularly attractive feature of this method is the possibility to estimate the effects of a treatment of interest by employing the random assignment from an unrelated existing experiment as a potentially invalid instrumental variable, as illustrated in the present study.

\section{References}

[1] Anderson, D.M. (2014). "In School and Out of Trouble? The Minimum Dropout Age and Juvenile Crime", Review of Economics and Statistics, 96 (2): 318-331.

[2] Angrist, J.D., Imbens, G.W., and Rubin D.B. (1996). "Identification of Causal Effects Using Instrumental Variables", Journal of the American Statistical Association, 91 (434): 444-455.

[3] Aizer, A. and Doyle J.J. (2015). "Juvenile Incarceration, Human Capital, and Future Crime: Evidence from Randomly Assigned Judges", Quarterly Journal of Economics, 759-804. 
[4] Bampasidou, M., Flores, C.A., Flores-Lagunes, A., and Parisian, D.J. (2014). "The Role of Degree Attainment in the Differential Impact of Job Corps on Adolescents and Young Adults", Research in Labor Economics, 40: 113-156.

[5] Blanco, G., Flores, C.A., and Flores-Lagunes, A. (2013). "Bounds on Average and Quantile Treatment Effects of Job Corps Training on Wages", Journal of Human Resources, 48 (3): 659-701.

[6] Chen, X. and Flores, C.A. (2015). "Bounds on Treatment Effects in the Presence of Sample Selection and Noncompliance: The Wage Effects of Job Corps", Journal of Business and Economic Statistics, 33 (4): 523-540.

[7] Chernozhukov, V., Lee, S., and Rosen, A. (2013). "Intersection Bounds: Estimation and Inference" Econometrica, 81 (2): 667-737.

[8] Cox, R. (2010). "Crime, Incarceration, and Employment in Light of the Great Recession", Review of Black Political Economy, 37 (3-4): 283-294.

[9] Eren, O. and Ozbeklik, S. (2013). "Who Benefits from JobCorps? A Distributional Analysis of an Active Labor Market Program", Journal of Applied Econometrics, 29: 586-611.

[10] Flores, C.A., Flores-Lagunes, A., Gonzalez, A., and Neumann, T. (2010). "Estimating the Effects of Length of Exposure to Instruction in a Training Program: The Case of Job Corps ", Review of Economics and Statistics, 94 (1): 153-171.

[11] Flores, C.A. and Flores-Lagunes, A. (2010). "Nonparametric Partial Identification of Causal Net and Mechanism Average Treatment Effects", working paper, California Polytechnic and State University at San Luis Obispo.

[12] Flores, C.A. and Flores-Lagunes, A. (2013). "Partial Identification of Local Average Treatment Effects With an Invalid Instrument", Journal of Business and Economic Statistics, 31 (4): 534545.

[13] Flores-Lagunes, A., Gonzalez, A., and Neumann, T. (2010). "Learning but not Earning? The Impact of Job Corps Training on Hispanic Youtht", Economic Inquiry, 48 (3): 651-667.

[14] Heckman, J.J. and LaFontaine, P.A. (2006). "Bias-Corrected Estimates of GED Returns", Journal of Labor Economics, 24 (3): 661-700. 
[15] Heckman, J.J. and LaFontaine, P.A. (2010). "The American High School Graduation Rate: Trends and Levels", Review of Economics and Statistics, 92 (22): 244-262.

[16] Hirano, K. and Porter, J.R. (2012). "Impossibility Results for Nondifferentiable Functionals", Econometrica, 80 (4): 1769-1790.

[17] Hjalmarrson, R., Holmlund, H., and Lindquist, M.J. (2015). "The Effect of Education on Criminal Convictions and Incarceration: Causal Evidence from Micro-data", Economic Journal, 125: $1290-1326$.

[18] Imbens, G.W. and Angrist, J.D. (1994). "Identification and Estimation of Local Average Treatment Effects", Econometrica, 62 (2): 467-475.

[19] Imbens, G.W. and Manski, C.F. (2004). "Confidence Intervals for Partially Identified Parameters", Econometrica, 72 (6): 1845-1857.

[20] Kearney, M.S., Harris, B.H., Jácome, E. and Parker, L. (2014). Ten Economic Facts about Crime and Incarceration in the United States, Washington, DC: The Hamilton ProjectBrookings Institution.

[21] Lang, K. and Kropp, D. (1986). "Human Capital Versus Sorting: The Effects of Compulsory Attendance Laws", Quarterly Journal of Economics, 101 (3): 609-624.

[22] Lee, D.S. (2009). "Training, Wages, and Sample Selection: Estimating Sharp Bounds on Treatment Effects", Review of Economic Studies, 76 (3): 1070-1102.

[23] Lochner, L. (2011). "Education Policy and Crime" in Cook, P.J., Ludwig, J., and McCrary, J. (eds.) Controlling Crime: Strategies and Tradeoffs, Chicago: University of Chicago Press for NBER.

[24] Lochner, L. and Moretti, E. (2004). "The Effect of Education on Crime: Evidence from Prison Inmates, Arrests and Self-reports", American Economic Review, 94 (1): 155-189.

[25] Machin, S., Marie, O., and Vujić, S. (2011). "The Crime Reducing Effect of Education", Economic Journal, 121 (552): 463-484.

[26] Needels, K. and Burghardt, J. (2000). National Job Corps Study: Telling It Straight: How Well Do Self-Reported Interview Data Measure Criminal Justice System Involvement?, Princeton, NJ: Mathematica Policy Research, Inc. 
[27] Rubin, D.B. (1980). "Discussion of 'Randomization Analysis of Experimental Data in the Fisher Randomization Test' by Basu", Journal of the American Statistical Association, 75 (371): $591-593$.

[28] Rubin, D.B. (1990). "Comment: Neyman (1923) and Causal Inference in Experiments and Observational Studies", Statistical Science, 5 (4): 472-480.

[29] Schochet, P.Z. (2001). National Job Corps Study: Methodological Appendices on the Impact Analysis, Princeton, NJ: Mathematica Policy Research Inc.

[30] Schochet, P.Z., Bellotti, J., Cao, R-J., Glazerman, S., et al. (2003). National Job Corps Study: Data Documentation and Public Use Files: Volume I, Princeton, NJ: Mathematica Policy Research Inc.

[31] Schochet, P.Z., Burghardt, J., and Glazerman, S. (2001). National Job Corps Study: The Impacts of Job Corps on Participants' Employment and Related Outcomes, Princeton, NJ: Mathematica Policy Research Inc.

[32] Schochet, P.Z., Burghardt, J., and McConnell, S. (2008). "Does Job Corps Work? Impact Findings from the National Job Corps Study", American Economic Review, 98 (5): 1864-1886.

[33] Stein, Z. and Kline, J. (1983). "Smoking, Alcohol and Reproduction", American Journal of Public Health, 73 (10): 1154-1156.

[34] Stevens, M. Jr. and Yang, D. (2014). "Compulsory Education and the Benefits of Schooling", American Economic Review, 104 (6): 1777-1792.

[35] Zhang, J.L., Rubin, D.B., and Mealli, F. (2008). "Evaluating the Effects of Job Training Programs on Wages Through Principal Stratification" in Fomby, T.B., et al. (eds.) Modelling and Evaluating Treatment Effects in Econometrics, Advances in Econometrics, vol. 21: 117-145, Bingley, UK: Emerald Publishing Limited. 